\title{
Morin hydrate attenuates the acrylamide-induced imbalance in antioxidant enzymes in a murine model
}

\author{
MAHENDRA PAL SINGH, REKHA JAKHAR and SUN CHUL KANG
}

Department of Biotechnology, Daegu University, Gyeongsan, Gyeongbuk 712-714, Republic of Korea

Received April 9, 2015; Accepted July 3, 2015

DOI: $10.3892 / \mathrm{ijmm} .2015 .2306$

\begin{abstract}
Liver diseases are among the most serious health issues nowadays. Hepatocellular carcinoma, one of the most lethal types of cancer worldwide, can be caused by chemicallyinduced oxidative stress. In the present study, we aimed to evaluate the protective effects of morin hydrate $(\mathrm{MH})$ against acrylamide (AA)-induced hepatotoxicity in male ICR mice. The mice were randomly allocated into 4 groups [the control, the group subcutaneously injected with AA alone $(50 \mathrm{mg} /$ $\mathrm{kg}$ body weight), the group subcutaneously injected with AA (50 $\mathrm{mg} / \mathrm{kg}$ body weight) and $\mathrm{MH}(5 \mathrm{mg} / \mathrm{kg}$ body weight) and the group subcutaneously injected with AA $(50 \mathrm{mg} / \mathrm{kg}$ body weight) and $\mathrm{MH}(15 \mathrm{mg} / \mathrm{kg}$ body weight) for 5 consecutive days]. Histopathological evaluations were performed and the levels of serum hepatic enzymes were analyzed to determine initial liver injury, and the mice in the AA-treated groups were compared with the mice receiving no treatment and with the mice administered MH in combination with AA. Furthermore, oxidative stress, hepatic inflammation and the levels of DNA damage-related markers were evaluated to determine the extent of liver damage induced by AA within a short-term period. The subcutaneous administration of AA induced severe hepatic injury, and combined treatment with $\mathrm{AA}$ and $\mathrm{MH}$ resulted in a significant improvement in all evaluated parameters. This recovery was most obvious in the group receiving AA and
\end{abstract}

Correspondence to: Professor Sun Chul Kang, Department of Biotechnology, College of Engineering, Daegu University, 201 Daegudae-Ro, Gyeongsan, Gyeongbuk 712-714, Republic of Korea E-mail: sckang@daegu.ac.kr

Abbreviations: AA, acrylamide; AA + MH5, acrylamide $50 \mathrm{mg} / \mathrm{kg}$ body weight plus morin hydrate $5 \mathrm{mg} / \mathrm{kg}$ body weight; AA + MH15, acrylamide $50 \mathrm{mg} / \mathrm{kg}$ body weight plus morin hydrate $15 \mathrm{mg} / \mathrm{kg}$ body weight; BER, base excision repair; CytP450, cytochrome $\mathrm{P} 450$; $\mathrm{GR}$, glutathione reductase; $\mathrm{HClO}$, hypochlorous acid; $\mathrm{MH}$, morin hydrate; NO, nitric oxide; NOS, nitric oxide synthase; PARP-1, poly(ADP-ribose) polymerase-1; ROS, reactive oxygen species; TMB, 3,3',5,5'-tetramethylbenzidine; TBA, thiobarbituric acid

Key words: acrylamide, antioxidants, DNA damage, morin hydrate, oxidative stress
$15 \mathrm{mg} / \mathrm{kg}$ body weight dose of MH. The findings of our study demonstrated that $\mathrm{MH}$ protected mice from severe hepatic injury induced by AA. Moreover, $\mathrm{MH}$ is a natural polyphenolic compound, and thus it has potential for use in the treatment of severe liver diseases, in place of many synthetic drugs.

\section{Introduction}

Liver diseases are of global concern, as due to lack of effective treatments, the prognosis is poor and the mortality rate is high (1). Although remarkable advances have been made in the field of modern medicine, hepatic diseases still remain a major worldwide health issue and thus the pursuit for novel and effective drugs without side-effects continues; for example, hyperoside has been shown to protect the liver against damage induced by carbon tetrachloride (2). The liver is a vital organ involved in various metabolic events, and the pathogenesis of liver disease due to oxidative stress and inflammation resulting from the accumulation of xenobiotics has been well established; in a previous study, the aqueous extract of Artemisia absinthium $L$. was shown to protect the livers of mice against chemically and immunologically-induced injury (3). Thus, it is important to discover methods with which to ameliorate the pathological symptoms of liver disease in order to prevent and treat liver injury. Natural polyphenolic compounds extracted from traditional plants are considered safe and effective alternative treatments to alleviate the symptoms of hepatotoxicity; for example, Moringa oleifera hydroethanolic extracts have been shown to effectively alleviate acetaminophen-induced hepatotoxicity in rats (4). Current research into hepatoprotective natural compounds is a major indicator for the screening systems that can trigger a safety evaluation in the early phase of drug discovery as the majority of toxic compounds are metabolized in the liver.

Acrylamide (AA) is a chemical compound that is widely used in the synthesis of polyacrylamides and other industrial chemicals. It has been demonstrated to induce oxidative stress, genotoxicity, neurotoxicity, carcinogenicity, developmental disorders and reproductive toxicity in rodents and other animals $(5,6)$. These effects are mediated through two major metabolic pathways: in the first pathway, the conjugation of AA with glutathione forms $\mathrm{N}$-acetyl-S-(3-amino-3-oxopropyl) cysteine and N-acetyl-S-(2-carbamoylethyl) cysteine, and in the second pathway, the epoxidation of AA into glycidamide occurs via cytochrome (Cyt)P450 (7), and the biotransforma- 
tion of AA to its epoxide derivative leads to the formation of glycidamide-DNA adducts, which leads to DNA damage $(8,9)$. Studies have investigated the use of pure natural compounds to control AA-induced toxicity, by regulating the levels of CytP450 and poly(ADP-ribose) polymerase (PARP)-1 (10,11).

Recently, there has been a growing interest in exploiting natural pure compounds due to their natural origin, affordable cost and minimal side-effects. Of these, morin hydrate $(\mathrm{MH}$; 2',3,4',5,7-pentahydroxyflavone), a yellowish pigment and potent flavonoid abundantly present in the plants of the Moraceae family (Fig. 1), is thought to be a major bioactive compound that may be used to prevent hepatotoxicity $(12,13)$. The protective effects of MH against oxidative stress and inflammation, which are the result of scavenging oxygen free radicals and hydroxyl radicals, have been investigated in previous studies (14-16). In addition, $\mathrm{MH}$ exerts various beneficial pharmacological effects, including the inhibition of xanthine oxidase (17), the prevention of low-density lipoprotein oxidation (18), immunomodulation (19) and anticancer activity (20).

In light of the aforementioned medical properties of $\mathrm{MH}$, in the present study, we thus aimed to investigate the hypothesis that MH may protect the liver against injury due to AA-induced toxicity by modulating the expression of inducible nitric oxide synthase (iNOS), endothelial nitric oxide synthase (eNOS), CytP450, PARP-1, antioxidant enzymes and other pathological parameters related to hepatotoxicity in a male murine model.

\section{Materials and methods}

Reagents. $\mathrm{MH}$ and AA were purchased from Sigma-Aldrich (St. Louis, MO, USA). Anti-rabbit PARP-1 (sc7150; Santa Cruz Biotechnology Inc., Santa Cruz, CA, USA), antiCytP450 (3084R100; BioVision, Inc., Milpitas, CA, USA), anti-eNOS (ab66127; Abcam, Cambridge, MA, USA), anti-iNOS (ab3523; Abcam), anti-catalase (sc50508; Santa Cruz Biotechnology Inc.), anti-glutathione reductase (GR; sc32886; Santa Cruz Biotechnology Inc.), anti-superoxide dismutase (SOD)1 (sc-11407; Santa Cruz Biotechnology Inc.), anti-SOD2 (sc-30080; Santa Cruz Biotechnology Inc.) and anti$\beta$-actin (sc-1616; Santa Cruz Biotechnology Inc.) antibodies, and horseradish peroxidase (HRP)-conjugated anti-rabbit immunoglobulins were purchased from Santa Cruz Biotechnology Inc. All chemicals, unless otherwise stated, were of the highest quality and were purchased from Sigma-Aldrich.

Animals and experimental design. Four-week-old male ICR mice, each weighing $20 \pm 5 \mathrm{~g}$, were provided by Orient Bio Inc. (Seongnam, Korea). All research procedures were carried out in accordance with the Guidelines for Animal Experimentation of Daegu University (Daegu, Korea). The animals were housed in an air-conditioned room at $22 \pm 2^{\circ} \mathrm{C}$ and $30 \pm 10 \%$ relative humidity. The animals were observed in terms of their general condition during a 7-day quarantine and acclimation period to confirm there were no abnormalities. After the quarantine period, the mice were randomly divided into 4 groups, each consisting of 6 animals as follows: group I (controls): mice were treated with the vehicle (normal physiological saline) by subcutaneous injection for 5 consecutive days; group II: mice were subcutaneously injected with AA $(50 \mathrm{mg} / \mathrm{kg}$ body weight) for 5 consecutive days; group III (AA + MH5): mice

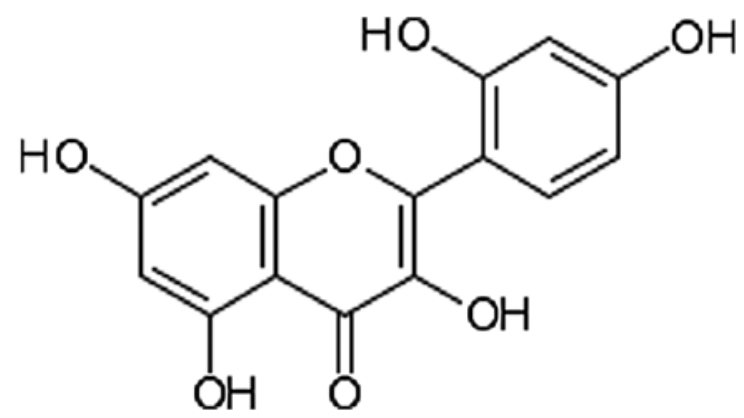

Figure 1. Chemical structure of morin hydrate.

were subcutaneously injected with AA ( $50 \mathrm{mg} / \mathrm{kg}$ body weight $)$ plus $\mathrm{MH}$ ( $5 \mathrm{mg} / \mathrm{kg}$ body weight) for 5 consecutive days; and group IV (AA + MH15): mice were subcutaneously injected with AA (50 mg/kg body weight) plus $\mathrm{MH}(15 \mathrm{mg} / \mathrm{kg}$ body weight) for 5 consecutive days. The doses of AA $(50 \mathrm{mg} / \mathrm{kg}$ body weight) and $\mathrm{MH}$ ( 5 and $15 \mathrm{mg} / \mathrm{kg}$ body weight) were selected based on their ability to induce alterations [changes in biochemical parameters, such as changes in alanine aminotransferase (ALT), aspartate aminotransferase (AST) and alkaline phosphatase (ALP) levels following treatment with $\mathrm{MH}]$ in mice, as previously described (21). On the 6th day, all the animals were sacrificed by cervical dislocation within $24 \mathrm{~h}$ of the final dose, and whole blood was collected in heparinized test tubes (Soyagreentec Co., Ltd., Seoul, Korea) and centrifuged at 2,500 $\mathrm{xg}$ for $15 \mathrm{~min}$ at $4^{\circ} \mathrm{C}$ to separate the serum, and then stored at $-80^{\circ} \mathrm{C}$ for further analysis. The livers were immediately excised from the mice and stored in liquid nitrogen, and a small portion of the liver tissue was fixed in $10 \%$ formalin for histopathological analysis.

Histopathological analysis. The liver tissues were fixed in $10 \%$ buffered formalin, processed with graded volumes of alcohol, embedded in paraffin, sectioned to a thickness of 4-5 microns and stained with hematoxylin and eosin (H\&E) for histopathological analysis. Histological examination was carried out under a light microscope (Nikon Eclipse TS200, Nikon Corp., Tokyo, Japan) at x20 magnification.

Determination of ALT, AST and ALP levels in serum. The concentration of the hepatic enzymes, ALT, AST and ALP, was measured in the serum samples obtained from all groups of mice. Enzyme activity was expressed as U/1, and measurements were carried out in accordance with the methods provided with the diagnostic kits (BioVision, Inc.).

Thiobarbituric acid reactive substances (TBARS) assay. The levels of malondialdehyde (MDA) in the liver tissue and serum were measured by examining the reaction of MDA with thiobarbituric acid (TBA), followed by UV-visible detection. Briefly, approximately $100 \mu \mathrm{l}$ of tissue homogenate or serum was mixed with $200 \mu 1$ of $10 \%$ TCA in 96-well plates, after which $100 \mu \mathrm{l}$ of working solution containing 67\% TBA were added. The mixture was incubated at $90^{\circ} \mathrm{C}$ for $20 \mathrm{~min}$ and cooled to room temperature. The samples were centrifuged at $2,000 \mathrm{x} g$ for $10 \mathrm{~min}$, and the absorbance of the supernatant was 
measured using a microplate reader (Bio-Tek Instruments Inc., Winooski, VT, USA) at $540 \mathrm{~nm}$.

Myeloperoxidase (MPO) activity assay. MPO activity in the liver tissue and serum samples was analyzed using 3,3',5,5'-tetramethylbenzidine (TMB; Sigma-Aldrich). Briefly, $10 \mu \mathrm{l}$ of the sample was combined with $80 \mu \mathrm{l}$ of $0.75 \mathrm{mM} \mathrm{H}_{2} \mathrm{O}_{2}$ and $110 \mu \mathrm{l}$ of TMB solution, after which the plate was incubated at $37^{\circ} \mathrm{C}$ for $5 \mathrm{~min}$. The reaction was terminated by the addition of $50 \mu \mathrm{l}$ of $2 \mathrm{M} \mathrm{H}_{2} \mathrm{SO}_{4}$, To estimate MPO activity, the absorption was measured at $450 \mathrm{~nm}$ using a microplate reader.

Determination of nitric oxide (NO) content in liver tissue and serum. The nitrite concentration in the liver tissue and serum was measured by the Griess reaction (22), and the calculated concentration was taken as an indicator of NO production. Briefly, the liver or serum samples were mixed with $100 \mu 1$ of Griess reagent (1\% sulfanilamide in 5\% phosphoric acid and $0.1 \%$ naphthylethylenediamine dihydrochloride in water) and then incubated at room temperature for $30 \mathrm{~min}$. The absorbance of the mixture was determined using a microplate reader at $540 \mathrm{~nm}$. Sodium nitrite was used to generate a standard curve.

Determination of total DNA damage in blood lymphocytes. To evaluate the level of DNA damage, a comet assay was performed as described in the study by Singh et al (23) with some modifications. This involved the embedding of cells in agarose, cell lysis in alkaline buffer and then the application of an electric current that pulled charged DNA from the nucleus so that relaxed and broken DNA fragments were able to migrate away from the intact DNA. Briefly, blood lymphocytes were isolated and suspended in $70 \mu \mathrm{l}$ of $1 \%$ (w/v) low melting point agarose in $\mathrm{PBS}(\mathrm{pH} 7.4)$ at $37^{\circ} \mathrm{C}$ and immediately pipetted onto frosted glass microscope slides pre-coated with a layer of $1 \%(\mathrm{w} / \mathrm{v})$ normal melting point agarose, after which a third layer of $75 \mu \mathrm{l}$ of $0.5 \%(\mathrm{w} / \mathrm{v})$ low melting point agarose in PBS was similarly applied. The slides were then allowed to set for $10 \mathrm{~min}$ on ice. To remove cellular proteins, the slides were immersed in lysis solution $\left(2.5 \mathrm{M} \mathrm{NaCl}, 0.1 \mathrm{M} \mathrm{Na}_{2}\right.$ EDTA, $10 \mathrm{mM}$ Tris, $\mathrm{pH} 10.0, \mathrm{NaOH}, 10 \% \mathrm{v} / \mathrm{v}$ dimethyl sulfoxide and $1 \% \mathrm{v} / \mathrm{v}$ Triton $\mathrm{X}-100$ ) at $4^{\circ} \mathrm{C}$ for $1 \mathrm{~h}$, and then placed in a double row in a $260-\mathrm{mm}$ wide horizontal electrophoresis tank containing electrophoresis buffer $(0.3 \mathrm{M} \mathrm{NaOH}$ and $1 \mathrm{mM} \mathrm{Na}_{2}$ EDTA) for $30 \mathrm{~min}$ before prior to electrophoresis at $40 \mathrm{~V}$ for $40 \mathrm{~min}$. The slides were then washed for $20 \mathrm{~min}$ with neutralizing solution $(0.4 \mathrm{M}$ Tris- $\mathrm{HCl}, \mathrm{pH} 7.5)$ before being stained with $50 \mu \mathrm{l}$ of ethidium bromide $(20 \mathrm{mg} / \mathrm{ml})$. The relative extent of cellular DNA damage was observed under an EPI fluorescence microscope (Nikon TS 100; Nikon Corp.) at x200 magnification.

Western blot analysis. Liver tissues stored in liquid nitrogen were lysed with RIPA lysis buffer (Sigma-Aldrich) and the protein concentrations were quantified by a Bradford protein assay. For western blot analysis, an equal amount of protein (50 $\mu \mathrm{g}$ in each lane) was subjected to SDS-polyacrylamide gel electrophoresis and then transferred onto polyvinyldenefluoride (PVDF) membranes (Roche Diagnostics, Indianapolis, IN, USA) by electroplating. The blots were probed with primary antibodies (anti-PARP-1, anti-CytP450, anti-eNOS, anti-iNOS, anti-catalase, anti-GR, anti-SOD-1, anti-SOD-2 and anti$\beta$-actin) followed by HRP-conjugated secondary antibody and then visualized by enhanced chemiluminescence (ECL) according to the recommended procedure (Amersham, Piscataway, NJ, USA).

Statistical analysis. All the data were calculated from 3 individual sets of experiments and the data are expressed as the means \pm standard deviation (SD). Statistical analyses were carried out using the Student's t-test. A P-value $<0.05$ was considered to indicate a statistically significant difference.

\section{Results}

MH treatment combats AA-induced tissue damage. The liver tissues were stained with H\&E for histological examination under a light microscope at $\times 20$ magnification. The liver sections obtained from the mice in group I (controls) exhibited normal hepatic cell architecture, granulated cytoplasm and intact nuclei (Fig. 2A), whereas the liver sections obtained from the mice in group II (treated with AA) exhibited cytoplasmic vacuolation, cell necrosis, central vein blood deposition and chronic periportal inflammatory cell infiltration as an indicator of active hepatitis (Fig. 2B). The liver sections obtained from the mice in groups III and IV (co-treated with AA and 5 or $15 \mathrm{mg}$ / $\mathrm{kg} \mathrm{MH}$, respectively) showed fewer pathological changes and an almost normal hepatic cell architecture, such as intact nuclei and reduced cytoplasmic vacuole size (Fig. 2C and D).

Treatment with $\mathrm{MH}$ reverses alterations in the levels of hepatic enzymes and biochemical parameters. To determine the effects of $\mathrm{MH}$ on AA-induced hepatic damage in mice, the activities of major oxidative stress-related parameters, such as ALT, AST and ALP were determined. Serum samples were analyzed to determine the levels of hepatic enzymes as shown in Fig. 3A. Exposure to AA significantly elevated the levels of ALT, AST and ALP in the serum compared with the control group $(\mathrm{P}<0.05)$. On the other hand, subcutaneous injections of $\mathrm{AA}$ and $\mathrm{MH}$ to the mice in groups III and IV, did produce an increase in the serum levels of these enzymes as compared with group II (AA treatment only; $\mathrm{P}<0.05$ ).

Furthermore, the levels of major oxidative stress-related markers, such as MDA and MPO were significantly increased in the AA-treated group compared the control group (MDA: liver, $\mathrm{P}<0.01$; serum, $\mathrm{P}<0.05$; MPO: liver, $\mathrm{P}<0.001$; serum, $\mathrm{P}<0.001$ ), whereas, the subcutaneous administration of $\mathrm{MH}$ ( 5 and $15 \mathrm{mg} / \mathrm{kg}$ ) together with AA did not allow the activity of MDA and MPO to increase in the mice in groups III and IV compared with the mice in group II (AA treatment only; $\mathrm{AA}+\mathrm{MH}$, MDA: liver, $\mathrm{P}<0.05$; serum, no significance; MPO: liver, $\mathrm{P}<0.05$; serum, $\mathrm{P}<0.01 ; \mathrm{AA}+\mathrm{MH} 15$, MDA: liver, $\mathrm{P}<0.01$; serum, $\mathrm{P}<0.05$; MPO: liver, $\mathrm{P}<0.001$; serum, $\mathrm{P}<0.001$ ) (Figs. 3B and 4A).

Treatment with $\mathrm{MH}$ reverses alterations in the expression of levels inflammatory markers. The effects of $\mathrm{MH}$ on the expression of levels inflammatory markers, such as eNOS and iNOS, in mouse liver tissue, was determined by western blot analysis. Treatment with AA (group II) increased the expression levels of eNOS $(\mathrm{P}<0.01)$ and iNOS $(\mathrm{P}<0.001)$ enzymes 

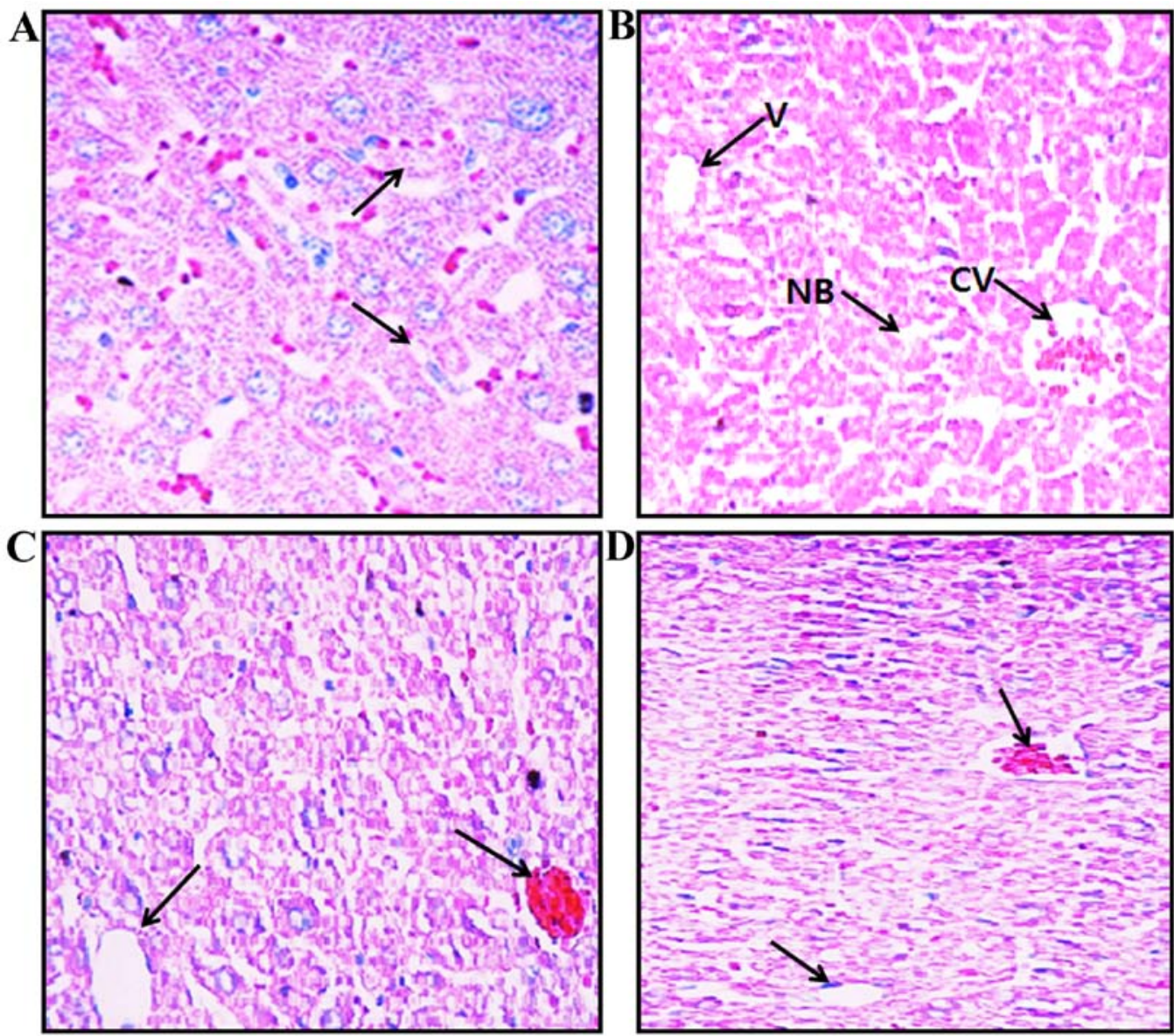

Figure 2. Histopathological examination of mouse liver tissue stained with H\&E at x20 magnification. (A) Control mice (group I), central vein and normal hepatocytes are evident. (B) AA-treated mice (group II), cytoplasmic vacuolation, cell necrosis, central vein blood deposition and chronic periportal inflammatory cell infiltration are present. (C) AA + MH5-treated mice (group III) and (D) AA + MH15-treated mice (group IV), AA-induced steatosis and other pathological changes were reduced. Necrotic bodies (NB), cental veins (CV) and vacuoles $(\mathrm{V})$ are indicated by black arrows. Images were captured using a light microscope at $\mathrm{x} 20$ magnification. AA, acrylamide; AA + MH5, acrylamide $50 \mathrm{mg} / \mathrm{kg}$ plus morin hydrate $5 \mathrm{mg} / \mathrm{kg}$; AA + MH15, acrylamide $50 \mathrm{mg} / \mathrm{kg}$ plus morin hydrate $15 \mathrm{mg} / \mathrm{kg}$.

A

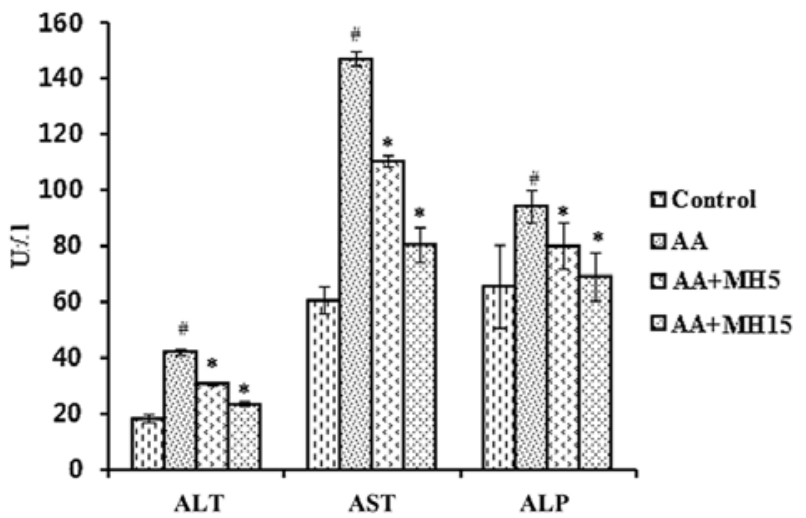

B

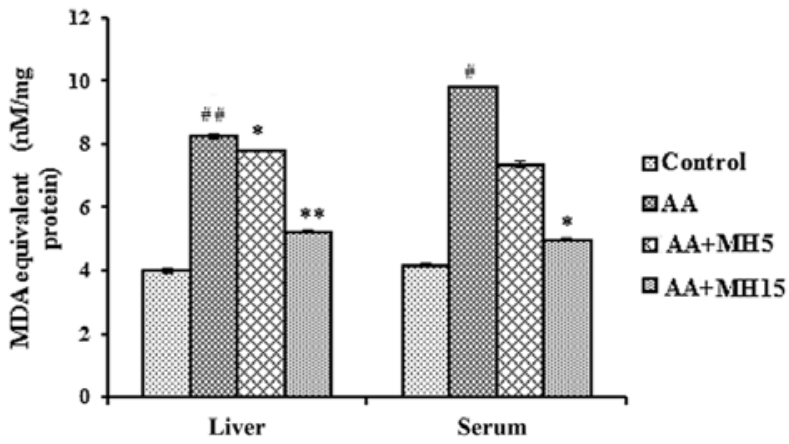

Figure 3. Effects of morin hydrate (MH) on the acrylamide (AA)-induced imbalance in serum alanine aminotransferase (ALT), aspartate aminotransferase (AST), alkaline phosphatase (ALP) levels and thiobarbituric acid reactive substances (TBARS) activity. (A) ALT, AST and ALP serum levels. (B) Lipid peroxidase activity. Data are represented as the means \pm SD for 6 animals in each group. Statistical significance was calculated using the Student's t-test. "P<0.05 and ${ }^{\# \#} \mathrm{P}<0.01$, statistically significant differences between the control and the AA-treated groups. ${ }^{*} \mathrm{P}<0.05$ and ${ }^{* * *} \mathrm{P}<0.01$, statistically significant differences between the AA-treated and the MH-treated groups. AA + MH 5 , acrylamide $50 \mathrm{mg} / \mathrm{kg}$ plus morin hydrate $5 \mathrm{mg} / \mathrm{kg}$; AA + MH15, acrylamide $50 \mathrm{mg} / \mathrm{kg}$ plus morin hydrate $15 \mathrm{mg} / \mathrm{kg}$.

as compared with the control group. Additionally, we also observed a significant increase in the activity of NO following treatment with AA in the liver and serum samples. However, the administration of MH ( 5 and $15 \mathrm{mg} / \mathrm{kg} / \mathrm{day}$, mainly the 

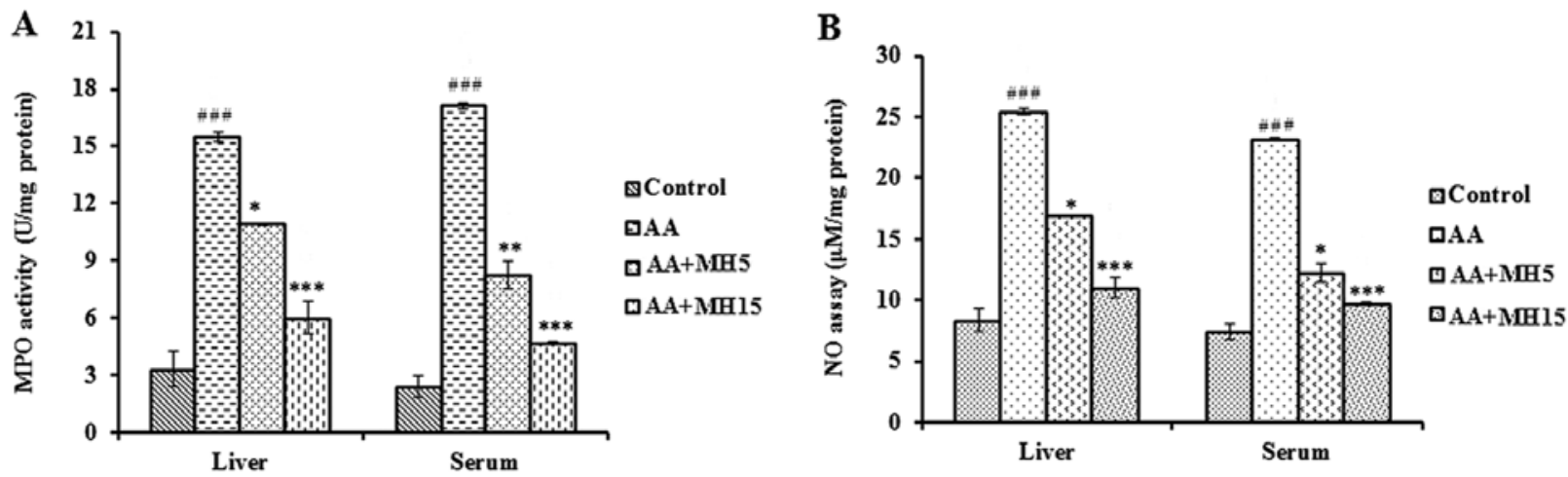

Figure 4. Effects of morin hydrate (MH) on the acrylamide (AA)-induced changes in myeloperoxidase (MPO) and nitric oxide (NO) content in liver homogenates and serum. (A) MPO activity in liver homogenates and serum. (B) Total NO content in liver homogenates and serum. Data are presented as the means \pm SD for 6 animals in each group. Statistical significance was calculated using the Student's t-test. ${ }^{\# \# \#} \mathrm{P}<0.001$, statistically significant differences between the control and the AA-treated groups. ${ }^{*} \mathrm{P}<0.05,{ }^{* * *} \mathrm{P}<0.01$ and ${ }^{* * * *} \mathrm{P}<0.001$, statistically significant differences between the AA-treated and the MH-treated groups. AA + MH5, acrylamide $50 \mathrm{mg} / \mathrm{kg}$ plus morin hydrate $5 \mathrm{mg} / \mathrm{kg} ; \mathrm{AA}+\mathrm{MH} 15$, acrylamide $50 \mathrm{mg} / \mathrm{kg}$ plus morin hydrate $15 \mathrm{mg} / \mathrm{kg}$

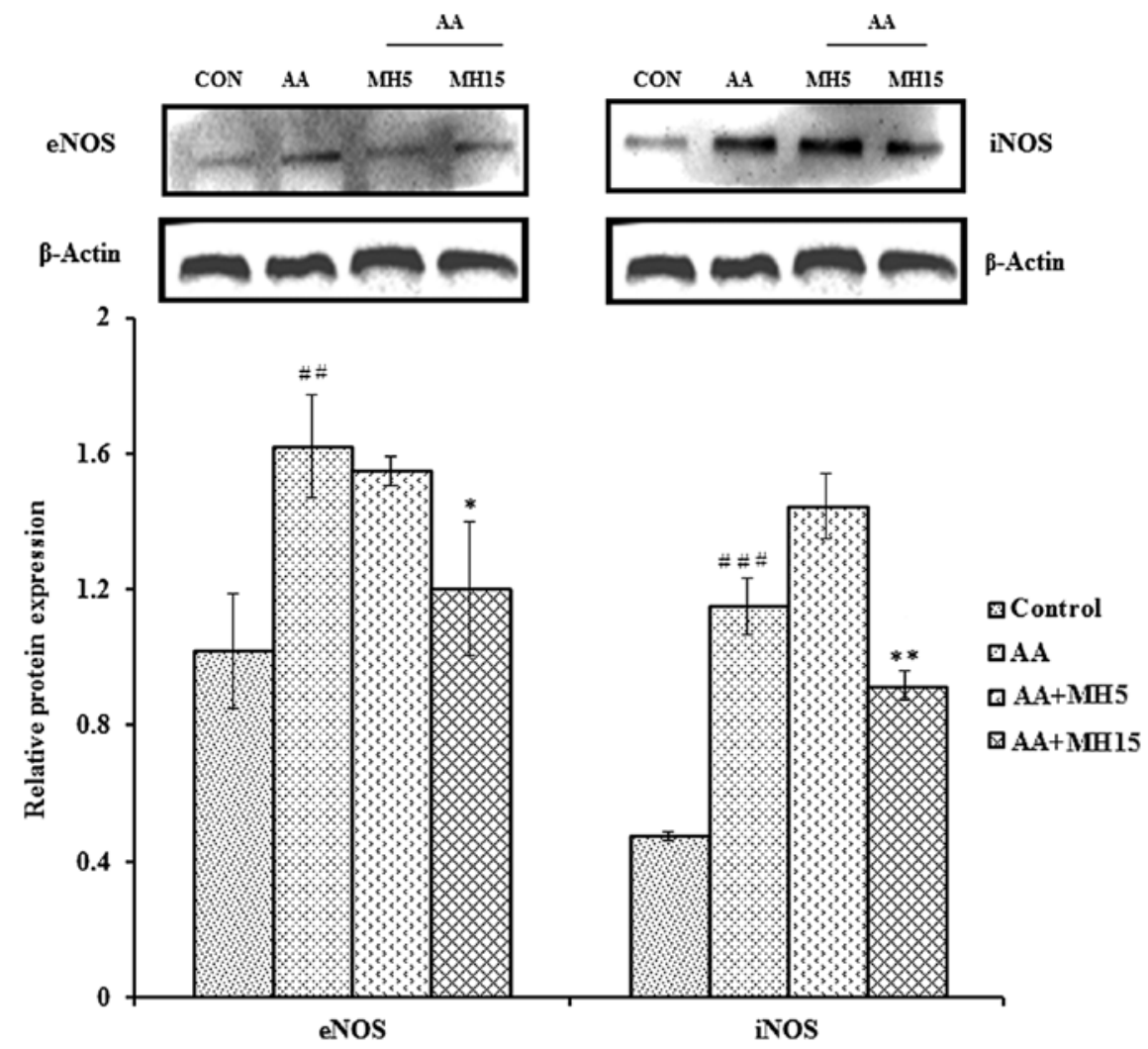

Figure 5. Effects of morin hydrate (MH) on acrylamide (AA)-induced inflammatory markers in mouse liver tissues. The expression of eNOS and iNOS was measured by western blot analysis and densitometric analysis. $\beta$-actin was used as a loading control. Data are presented as the means \pm SD for 6 animals in each group. Statistical significance was calculated using the Student's t-test. ${ }^{\# \#} \mathrm{P}<0.01$ and ${ }^{\# \# \#} \mathrm{P}<0.001$, statistically significant differences between the control and the AA-treated groups. ${ }^{*} \mathrm{P}<0.05$ and $^{* *} \mathrm{P}<0.01$, statistically significant differences between the AA-treated and the MH-treated groups. AA + MH5, acrylamide $50 \mathrm{mg} /$ $\mathrm{kg}$ plus morin hydrate $5 \mathrm{mg} / \mathrm{kg}$; AA + MH15, acrylamide $50 \mathrm{mg} / \mathrm{kg}$ plus morin hydrate $15 \mathrm{mg} / \mathrm{kg}$.

larger dose of $15 \mathrm{mg} / \mathrm{kg} / \mathrm{day})$ together with AA to the mice in groups III and IV, reversed the increase in the expression of eNOS (AA + MH5, no significant change; AA + MH15, $\mathrm{P}<0.05)$ and iNOS $(\mathrm{P}<0.01)$ enzymes, as well as NO activity (AA + MH5: liver, $\mathrm{P}<0.05$; serum, $\mathrm{P}<0.05$; AA + MH15: liver, $\mathrm{P}<0.001$; serum, $\mathrm{P}<0.001)$ compared with the AA-treated group (Figs. 4B and 5). However, iNOS epxression did not show any significant change following treatment with $5 \mathrm{mg} / \mathrm{kg}$
$\mathrm{MH}$ in comparison to the AA-treated group. In fact, there was a slight increase in iNOS expression in the AA + MH5 group. Treatment with MH was more effective in inhibiting iNOS expression at the concentration of $15 \mathrm{mg} / \mathrm{kg}$.

Treatment with $M H$ reverses alterations in the expression of PARP-1 and CytP450. To determine the protective effects of MH against oxidative stress-induced DNA damage, the expres- 


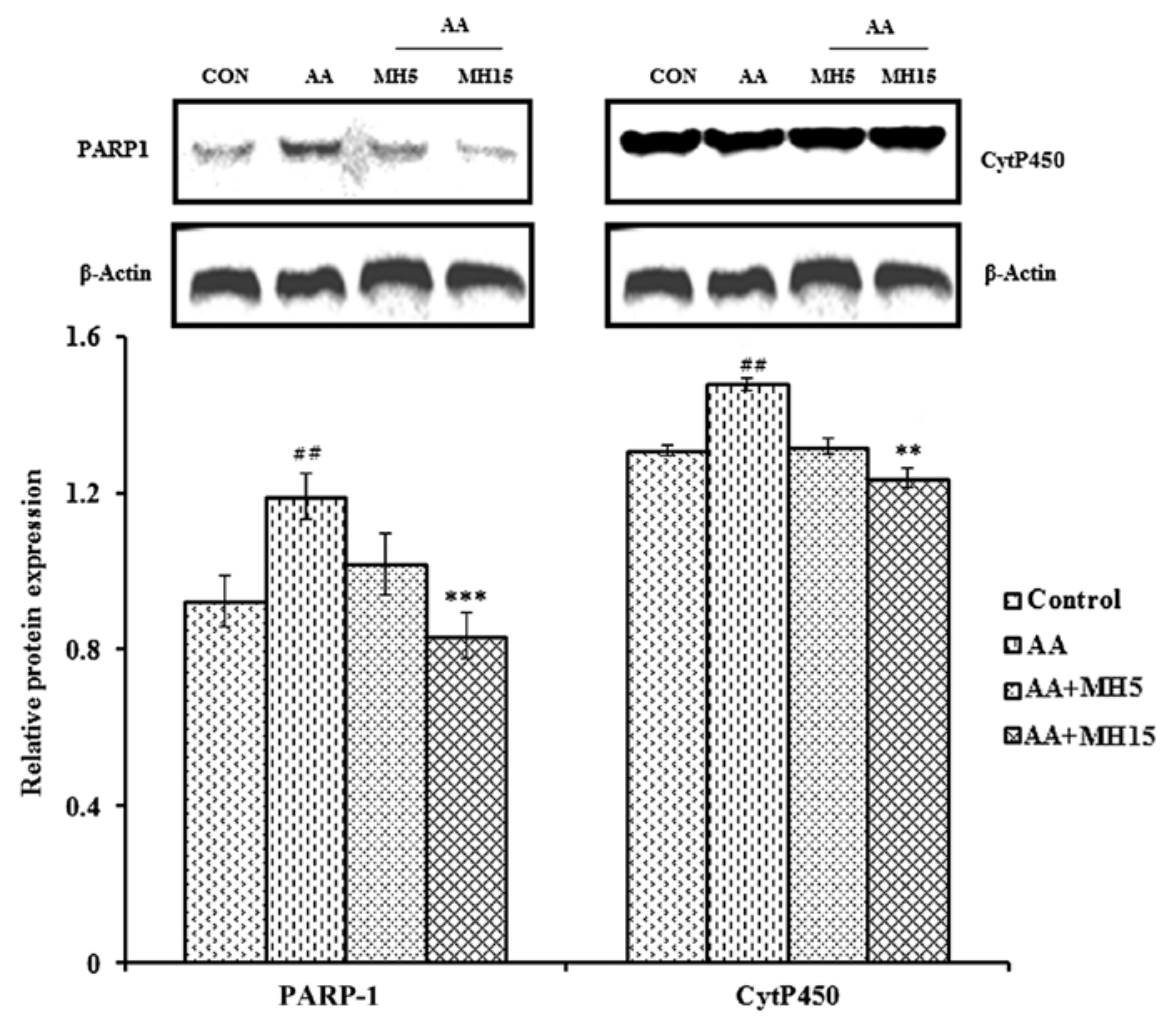

Figure 6. Effects of morin hydrate (MH) on acrylamide (AA)-induced expression of PARP-1 and CytP450 markers in mouse liver tissue. The expression of PARP-1 and CytP450 was measured by western blot analysis and densitometric analysis. $\beta$-actin was used as a loading control. Data are presented as the means \pm SD for 6 animals in each group. Statistical significance was calculated using the Student's t-test. ${ }^{\# \#} \mathrm{P}<0.01$, statistically significant differences between the control and the AA-treated groups. ${ }^{* *} \mathrm{P}<0.01$ and ${ }^{* * * *} \mathrm{P}<0.001$, statistically significant differences between the AA-treated and the MH-treated groups. AA + MH5, acrylamide $50 \mathrm{mg} / \mathrm{kg}$ plus morin hydrate $5 \mathrm{mg} / \mathrm{kg}$; AA + MH15, acrylamide $50 \mathrm{mg} / \mathrm{kg}$ plus morin hydrate $15 \mathrm{mg} / \mathrm{kg}$.

sion levels of DNA damage repair and xenobiotic detoxifying markers were analyzed by western blot anlaysis. The expression levels of PARP-1 and CytP450 were significantly elevated in the liver tissue obtained from the AA-treated group compared the control group (both $\mathrm{P}<0.01$; Fig. 6). Elevated NO levels led to oxidative stress-mediated DNA damage and PARP-1 accumulation in response to AA treatment. The subcutaneous injection of $\mathrm{MH}$ together with AA (at the dose of $15 \mathrm{mg}$ / $\mathrm{kg}$ /day) reversed the increase in the expression of PARP-1 and CytP450 induced by AA (AA + MH5; PARP-1, no significant change; CytP450, no significant change; AA + MH15: PARP-1, $\mathrm{P}<0.001$; CytP450, $\mathrm{P}<0.01$ ). As regards the expression of PARP-1, following treatment with $\mathrm{MH}$ at $15 \mathrm{mg} / \mathrm{kg} /$ day, the levels returned almost basal levels.

Treatment with $M H$ protects against $A A$-induced DNA damage in lymphocytes. The DNA-protective effects of MH were analyzed in mouse blood lymphocytes by comet assay. The changes in comet tail lengths, area and diameter were easily identified between the AA-treated and the control groups of animals. The comet area and head diameter in the AA-treated group were significantly higher than those of the control group $(\mathrm{P}<0.01)$ (Fig. 7A, B, E and F). However, co-treatment with MH plus AA decreased the comet area and head diameter in groups III and IV compared with the AA-treated group (AA + MH5, P<0.01; AA + MH15, P<0.001; Fig. 7C-F). The blood lymphocytes exhibited almost normal or intact nuclei at the higher dose of $\mathrm{MH}$.
Treatment with MH metabolically balances the expression of antioxidant enzymes. To determine the antioxidant potential of $\mathrm{MH}$, the expression levels of the antioxidant enzymes, SOD1, SOD2, catalase and GR, were determined by western blot analysis (Fig. 8). During this experiment, an imbalance in antioxidant enzymes was observed. The levels of antioxidant enzymes were significantly elevated in the liver tissue from the mice in the AA-treated group as compared with the control group mice (SOD1, catalase and GR, $\mathrm{P}<0.001$; SOD2, $\mathrm{P}<0.01$ ). Elevated levels of these antioxidant enzymes may be associated with hyperoxic conditions due to increased levels of reactive oxygen species (ROS). The administration of MH ( 5 and $15 \mathrm{mg} / \mathrm{kg} /$ day) in combination with AA, was found to be effective at balancing the levels of these enzymes in the liver tissues of the mice in groups III and IV, particularly at the higher dose of MH.

\section{Discussion}

The present study demonstrated that short-term exposure to AA $(50 \mathrm{mg} / \mathrm{kg})$ induced severe liver damage and an imbalance in antioxidant enzymes due to the accumulation of ROS and the dysfunction of the antioxidative defense system in liver cells. The production of free radicals was inhibited by MH supplementation, which protected the hepatocytes from oxidative damage. The higher dose of MH (15 mg/kg body weight) effectively reduced liver pathogenicity, and based on these facts, it can be hypothesized that $\mathrm{MH}$ exerts therapeutic effects against the AA-induced imbalance in antioxidant enzymes in mouse liver. 

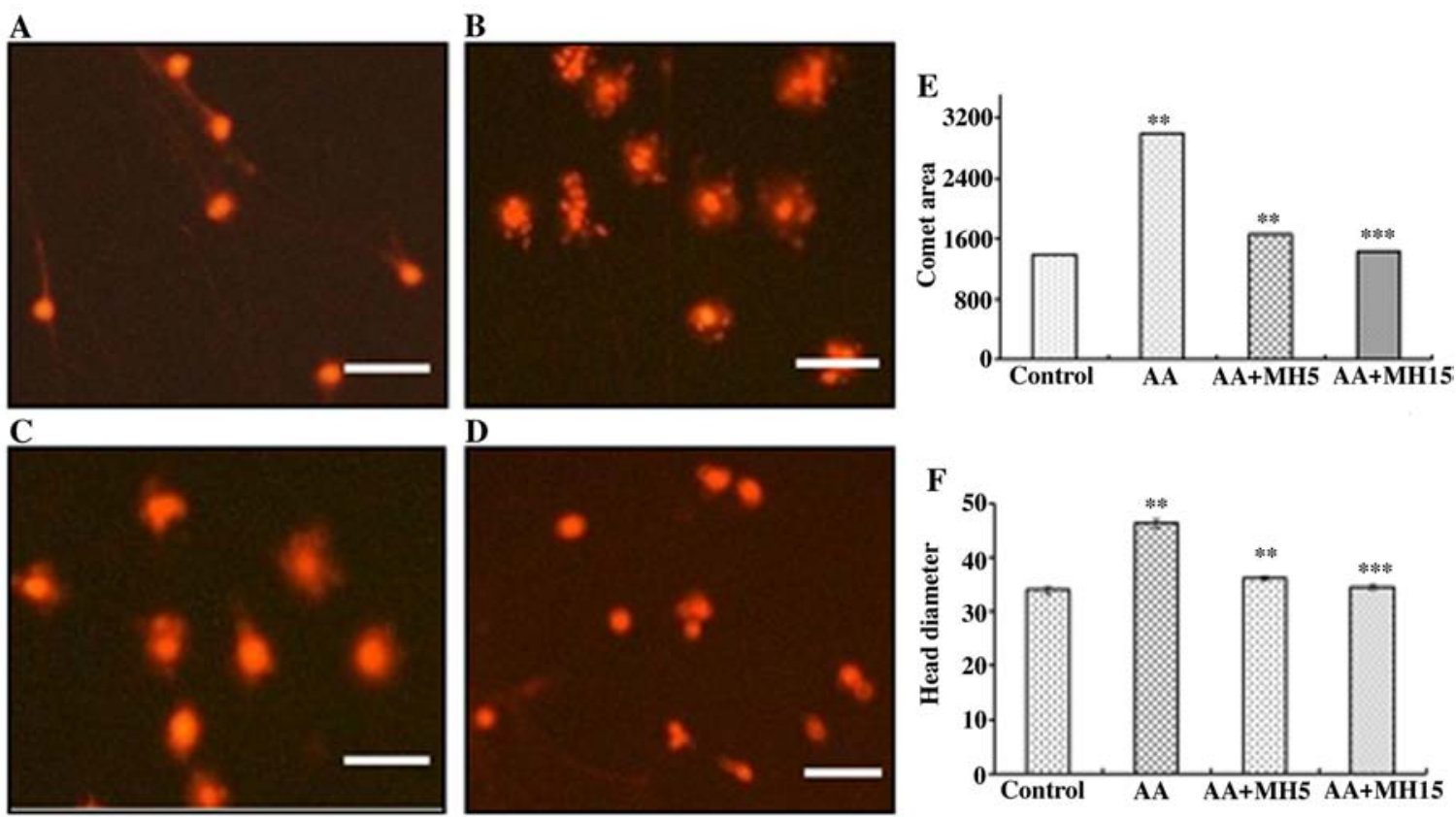

Figure 7. Effects of morin hydrate (MH) on acrylamide (AA)-induced DNA damage in mouse blood lymphocytes examined. (A-D) Samples were analyzed using the comet assay. Lymphocytes from (A) the control group with no comets, (B) AA-treated mice with comet tails, (C) AA + MH5-treated mice with reduced comet tails and (D) AA + MH15-treated mice with no comet tails ( $\mathrm{n}=6$ ). Scale bar $0.1 \mathrm{~mm}$ (x20 magnification). (E) Graphical representation of the comet area. (F) Graphical representation of the comet head diameter. Each value represents the mean \pm SD of triplicates compared to control and AA-treated mice (n=6) Statistical significance was calculated using the Student's $t$-test. ${ }^{\# \#} \mathrm{P}<0.01$, statistically significant differences between the control and the AA-treated groups. ${ }^{* * *} \mathrm{P}<0.01$ and ${ }^{* * * *} \mathrm{P}<0.001$, statistically significant differences between the AA-treated and the MH-treated groups. AA + MH5, acrylamide $50 \mathrm{mg} / \mathrm{kg}$ plus morin hydrate $5 \mathrm{mg} / \mathrm{kg}$; AA + MH15, acrylamide $50 \mathrm{mg} / \mathrm{kg}$ plus morin hydrate $15 \mathrm{mg} / \mathrm{kg}$.

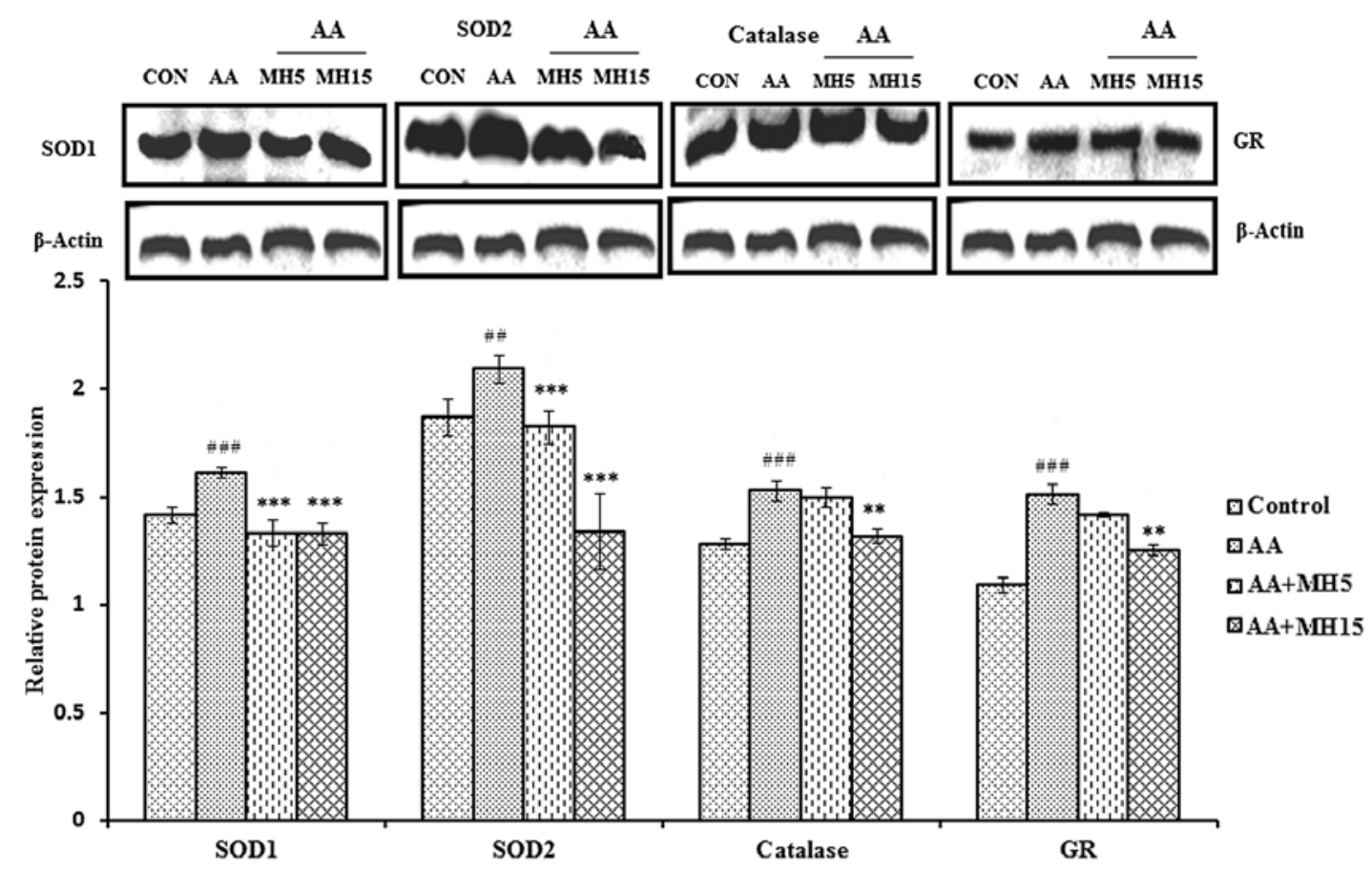

Figure 8. Effects of morin hydrate (MH) on AA-induced antioxidant markers in mouse liver tissues treated with acrylamide (AA) analyzed by western blot analysis and densitometric analysis and densitometric analysis of superoxide dismutase (SOD)1, SOD2, catalase and glutathione reductase (GR). $\beta$-actin was used as a loading control. Data are presented as the means \pm SD for 6 animals in each group. Statistical significance was calculated using the Student's t-test. ${ }^{\# \#} \mathrm{P}<0.01$ and ${ }^{\# \# "} \mathrm{P}<0.001$, statistically significant differences between the control and the AA-treated groups. ${ }^{* *} \mathrm{P}<0.01$ and ${ }^{* * * *} \mathrm{P}<0.001$, statistically significant differences between the AA-treated and the MH-treated groups. AA + MH5, acrylamide $50 \mathrm{mg} / \mathrm{kg}$ plus morin hydrate $5 \mathrm{mg} / \mathrm{kg}$; AA + MH15, acrylamide $50 \mathrm{mg} / \mathrm{kg} \mathrm{plus} \mathrm{morin} \mathrm{hydrate} 15 \mathrm{mg} / \mathrm{kg}$.

The major function of the liver is to detoxify xenobiotic substances. However, the accumulation of high amounts of toxic chemicals through daily food consumption has become a serious threat to human life (24). The hepatic enzymes, ALT, AST and ALP, are often used as biochemical parameters to detect liver injury. The increased production of hepatic 
enzymes in the serum is an indicator of enhanced cell permeability, cell necrosis, fat deposition, vacuolation and capillary blood deposition of hepatocytes (25). In the present study, the activity of the ALT, AST and ALP enzymes was significantly elevated in the AA-treated mice due to the severe damage sustained to the tissue membranes. However, the production of the ALT, AST and ALP enzymes was decreased in the serum and liver homogenates obtained from the mice in groups III and IV following co-treatment with $\mathrm{MH}$. This regulatory effect of $\mathrm{MH}$ on AA-induced hepatotoxicity may be due to the ability of $\mathrm{MH}$ to promote glutathione conjugation with toxic metabolites generated by the CytP450 pathway $(7,26)$. The above findings suggest that $\mathrm{MH}$ protects liver hepatocytes from AA-induced cell necrosis, capillary blood deposition and cell vacuolation.

Furthermore, we focused on the generation of AA-induced free radicals which may be causing damage to the liver. It has already been reported that free radicals are more reactive than molecular elements and cause severe damage to nucleic acids, proteins and cell membranes (27). These radicals generally include superoxide anions, hydrogen peroxide, hydroxyl radicals, $\mathrm{NO}$ and $\mathrm{ONOO}^{-}$, which are generated by the incomplete reduction of oxygen and nitrogen elements (28). The levels of MPO, an endogenous lysosomal enzyme that removes $\mathrm{H}_{2} \mathrm{O}_{2}$ and catalyzes the formation of toxic $\mathrm{HClO}$ (29), were significantly increased in the AA-treated group in our study. Furthermore, we elucidated the free radical scavenging potential of $\mathrm{MH}(15 \mathrm{mg} / \mathrm{kg})$ to regulate the activity of MPO and NO induced by AA treatment. Studies have also suggested a correlation between neutrophils and TBARS, as the latter is an indicator of free radical-mediated lipid peroxidation $(30,31)$. Our results demonstrated that the subcutaneous injection of $\mathrm{MH}$ together with AA significantly regulated the TBARS levels compared the AA-treated group.

The production of NO is dependent on the oxidation of the terminal guanido nitrogen atoms of L-arginine by a group of enzymes termed NOS. NO reacts with a variety of radicals and substances, such as $\mathrm{H}_{2} \mathrm{O}_{2}$ and $\mathrm{HClO}$ to yield a line of derivatives, including $\mathrm{N}_{2} \mathrm{O}_{3}, \mathrm{NO}_{2}{ }^{-}$and $\mathrm{NO}_{3}{ }^{-}$. It can also react with $\mathrm{O}_{2}^{-}$, leading to the formation of $\mathrm{ONOO}^{-}$and subsequent DNA damage (32). Our findings suggested that the increased expression of eNOS and iNOS in the AA-treated group resulted in a severe inflammation in hepatocytes due to NO production. The subcutaneous administration of $\mathrm{MH}(15 \mathrm{mg} / \mathrm{kg})$ together with and AA significantly downregulated the expression of eNOS and iNOS which suggests $\mathrm{MH}$ exerts an anti-inflammatory effect against AA-induced NO production and hepatic injury.

The PARP family of proteins consists of 18 members which are characterized by poly(ADP-ribosyl)ation activity. PARP-1 accounts for at least $80 \%$ of total cellular activity and constitutes the response against the DNA damage (33). Its role in single-stranded break (SSB) repair via base excision repair (BER) is most certainly based on $\mathrm{NAD}^{+}$depletion, and may be responsible for cellular damage and apoptosis (34). Our findings indicated that, exposure to AA (group II animals) induced oxidative stress-mediated DNA damage that was identified based on a significant increase in comet tail length. In response to DNA damage, the expression of PARP-1 increased significantly. On the other hand, co-treatment with MH significantly decreased PARP-1 expression in mouse hepatocytes and this demonstrated the genoprotective effects of $\mathrm{MH}$ against AA-induced DNA damage in blood lymphocytes.

CytP450 is considered aprimary defense system against foreign chemicals. It mainly detoxifies xenobiotics, and participate in hydrolysis, oxidation or reduction mechanisms which protect the cells from pathological conditions $(7,35)$. To combat against AA toxicity, the levels of CytP450 increase in hepatocytes in order to metabolize AA into glycidamide by biotransformation (36). This metabolically active counterpart of AA leads to DNA damage and ROS generation (37). Our study demonstrated that the subcutaneous injection of $\mathrm{MH}$ together with AA regulated the expression of CytP450 in the mouse liver tissues. The reduced expression of CytP450 offers evidence to support the attenuating potential of $\mathrm{MH}$ against AA-induced toxicity in the liver tissue of male mice.

The human body possesses an effective antioxidant defense system against free radicals which protects against oxidative stress-induced cellular damage by regulating the various endogenous enzymatic and non-enzymatic antioxidants, such as SOD1, SOD2, catalase and GR $(38,39)$. In the present study, we demonstrated that exposure to AA significantly elevated the levels of SOD1, SOD2, catalase and GR due to an imbalance in antioxidant enzymes that may be associated with hyperoxic conditions due to increased ROS production. The enhanced levels of antioxidant enzymes following exposure to AA (group II mice) may also be attributed to increased lipid peroxidation $(21,40)$. SOD, catalase, GR and other antioxidant enzymes constitute a mutually supportive team of defenders against various noxious stimuli, including oxidative stress. The administration of $\mathrm{MH}$ together with AA did not allow the elevation of the antioxidant enzymes compared with the AA-treated group. These findings suggest that $\mathrm{MH}$ possesses a regulatory potential against an imbalance in antioxidant enzymes induced by $\mathrm{AA}$ in liver tissue.

In conclusion, the findings of our study suggested that AA-induced pathogenicity in the livers of male ICR mice was attenuated by regulation of the histopathological and biochemical parameters following the subcutaneous injection of $\mathrm{MH}$ at a dose of $15 \mathrm{mg} / \mathrm{kg}$. In addition, MH did not allow oxidative stress-induced DNA damage to occur and regulated PARP-1 and CytP450 expression. Thus, it can be concluded that $\mathrm{MH}$ has hepatoprotective potential against AA-induced toxicity by scavenging free radicals and blocking the epoxidation mechanism. Therefore, supplementation with $\mathrm{MH}$, as a food or drug, may provide a possible future therapeutic intervention for individuals with liver disease and may offer potential health benefits.

\section{Acknowledgements}

This study was supported by the Daegu University Research Grant, 2012.

\section{References}

1. Seeff LB, Lindsay KL, Bacon BR, Kresina TF and Hoofnagle JH: Complementary and alternative medicine in chronic liver disease. Hepatology 34: 595-603, 2001.

2. Choi JH, Kim DW, Yun N, Choi JS, Islam MN, Kim YS and Lee SM: Protective effects of hyperoside against carbon tetrachloride-induced liver damage in mice. J Nat Prod 74: 1055-1060, 2011. 
3. Amat $\mathrm{N}$, Upur $\mathrm{H}$ and Blazeković B: In vivo hepatoprotective activity of the aqueous extract of Artemisia absinthium L. against chemically and immunologically induced liver injuries in mice. J Ethnopharmacol 131: 478-484, 2010.

4. Fakurazi S, Sharifudin SA and Arulselvan P: Moringa oleifera hydroethanolic extracts effectively alleviate acetaminopheninduced hepatotoxicity in experimental rats through their antioxidant nature. Molecules 17: 8334-8350, 2012.

5. Tareke E, Rydberg P, Karlsson P, Eriksson S and Törnqvist M: Analysis of acrylamide, a carcinogen formed in heated foodstuffs. J Agric Food Chem 50: 4998-5006, 2002.

6. Johnson KA, Gorzinski SJ, Bodner KM, Campbell RA, Wolf CH, Friedman MA and Mast RW: Chronic toxicity and oncogenicity study on acrylamide incorporated in the drinking water of Fischer 344 rats. Toxicol Appl Pharmacol 85: 154-168, 1986.

7. Zhang L, Wang E, Chen F, Yan H and Yuan Y: Potential protective effects of oral administration of allicin on acrylamide-induced toxicity in male mice. Food Funct 4: 1229-1236, 2013.

8. Segerbäck D, Calleman CJ, Schroeder JL, Costa LG and Faustman EM: Formation of N-7-(2-carbamoyl-2-hydroxyethyl) guanine in DNA of the mouse and the rat following intraperitoneal administration of $\left[{ }^{14} \mathrm{C}\right]$ acrylamide. Carcinogenesis 16 : 1161-1165, 1995.

9. Kohen R and Nyska A: Oxidation of biological systems: oxidative stress phenomena, antioxidants, redox reactions, and methods for their quantification. Toxicol Pathol 30: 620-650, 2002

10. Taubert D, Glöckner R, Müller D and Schömig E: The garlic ingredient diallyl sulfide inhibits cytochrome P450 2E1 dependent bioactivation of acrylamide to glycidamide. Toxicol Lett 164: 1-5, 2006.

11. Alturfan AA, Tozan-Beceren A, Sehirli AO, Demiralp E, Sener G and Omurtag GZ: Resveratrol ameliorates oxidative DNA damage and protects against acrylamide-induced oxidative stress in rats. Mol Biol Rep 39: 4589-4596, 2012.

12. Xie MX, Long M, Liu Y, Qin C and Wang YD: Characterization of the interaction between human serum albumin and morin. Biochim Biophys Acta 1760: 1184-1191, 2006.

13. Venu Gopal J: Morin hydrate: Botanical origin, pharmacological activity and its applications: A mini-review. Pharmacogn JRev 5: 123-126, 2013

14. Caillet S, Yu H, Lessard S, Lamoureux G, Ajdukovic D and Lacroix M: Fenton reaction applied for screening natural antioxidants. Food Chem 100: 542-552, 2007.

15. Gálvez J, Coelho G, Crespo ME, Cruz T, Rodríguez-Cabezas ME, Concha A, Gonzalez M and Zarzuelo A: Intestinal anti-inflammatory activity of morin on chronic experimental colitis in the rat. Aliment Pharmacol Ther 15: 2027-2039, 2001

16. Choi CW, Kim SC, Hwang SS, Choi BK, Ahn HJ, Lee MY, Park SH and Kim SK: Antioxidant activity and free radical scavenging capacity between Korean medicinal plants and flavonoids by assay guided comparison. Plant Sci 163: 1161-1168, 2002.

17. Yu Z, Fong WP and Cheng CHK: The dual actions of morin (3,5,7,2', '-pentahydroxyflavone) as a hypouricemic agent: uricosuric effect and xanthine oxidase inhibitory activity. J Pharmacol Exp Ther 316: 169-175, 2006.

18. Lian TW, Wang L, Lo YH, Huang IJ and Wu MJ: Fisetin, morin and myricetin attenuate CD36 expression and oxLDL uptake in U937-derived macrophages. Biochim Biophys Acta 1781: 601-609, 2008.

19. Jakhar R, Paul S, Chauhan AK and Kang SC: Morin hydrate augments phagocytosis mechanism and inhibits LPS induced autophagic signaling in murine macrophage. Int Immunopharmacol 22: 356-365, 2014

20. Manna SK, Aggarwal RS, Sethi G, Aggarwal BB and Ramesh GT: Morin (3,5,7,2',4'-Pentahydroxy flavone) abolishes nuclear factor- $\kappa \mathrm{B}$ activation induced by various carcinogens and inflammatory stimuli, leading to suppression of nuclear factor- $\kappa \mathrm{B}$-regulated gene expression and up-regulation of apoptosis. Clin Cancer Res 13: 2290-2297, 2007.
21. Sreedharan V, Venkatachalam KK and Namasivayam N: Effect of morin on tissue lipid peroxidation and antioxidant status in 1, 2-dimethylhydrazine induced experimental colon carcinogenesis. Invest New Drugs 27: 21-30, 2009.

22. Griess P: Bemerkungen zu, der abhandlung der HH Weselsky und Benedikt: Ueber einige azoverbindungen. Chem Ber 12: 426-428, 1879 (In German) .

23. Singh NP, McCoy MT, Tice RR and Schneider EL: A simple technique for quantitation of low levels of DNA damage in individual cells. Exp Cell Res 175: 184-191, 1988.

24. Wu CC, Sheen LY, Chen HW, Kuo WW, Tsai SJ and Lii CK: Differential effects of garlic oil and its three major organosulfur components on the hepatic detoxification system in rats. J Agric Food Chem 50: 378-83, 2002.

25. Goldberg DM and Watts C: Serum enzyme changes as evidence of liver reaction to oral alcohol. Gastroenterology 49: 256-261, 1965.

26. Fakurazi S, Hairuszah I and Nanthini U: Moringa oleifera Lam prevents acetaminophen induced liver injury through restoration of glutathione level. Food Chem Toxicol 46: 2611-2615, 2008.

27. Alzahrani HAS: Protective effect of l-carnitine against acrylamide-induced DNA damage in somatic and germ cells of mice. Saudi J Biol Sci 18: 29-36, 2011.

28. Lobo V, Patil A, Phatak A and Chandra N: Free radicals, antioxidants and functional foods: Impact on human health. Pharmacogn Rev 4: 118-126, 2010.

29. Sawayama Y, Miyazaki Y, Ando K, Horio K, Tsutsumi C, Imanishi D, Tsushima H, Imaizumi Y, Hata T, Fukushima T, et al: Expression of myeloperoxidase enhances the chemosensitivity of leukemia cells through the generation of reactive oxygen species and the nitration of protein. Leukemia 22: 956-964, 2008.

30. Zhang R, Kang KA, Piao MJ, Maeng YH, Lee KH, Chang WY, You HJ, Kim JS, Kang SS and Hyun JW: Cellular protection of morin against the oxidative stress induced by hydrogen peroxide. Chem Biol Interact 177: 21-27, 2009.

31. Belboul A, Löfgren C, Storm C and Jungbeck M: Heparin-coated circuits reduce occult myocardial damage during CPB: a randomized, single blind clinical trial. Eur J Cardiothorac Surg 17: 580-586, 2000

32. Ames BN: DNA damage from micronutrient deficiencies is likely to be a major cause of cancer. Mutat Res 475: 7-20, 2001.

33. Amé JC, Spenlehauer C and de Murcia G: The PARP superfamily. BioEssays 26: 882-893, 2004.

34. Fisher AE, Hochegger H, Takeda S and Caldecott KW: Poly(ADPribose) polymerase 1 accelerates single-strand break repair in concert with poly(ADP-ribose) glycohydrolase. Mol Cell Biol 27: 5597-5605, 2007.

35. Miller MJ, Carter DE and Sipes IG: Pharmacokinetics of acrylamide in Fisher-344 rats. Toxicol Appl Pharmacol 63: 36-44, 1982.

36. Solomon JJ, Fedyk J, Mukai F and Segal A: Direct alkylation of 2'-deoxynucleosides and DNA following in vitro reaction with acrylamide. Cancer Res 45: 3465-3470, 1985.

37. Adler ID, Ingwersen I, Kliesch U and el Tarras A: Clastogenic effects of acrylamide in mouse bone marrow cells. Mutat Res 206: 379-385, 1988.

38. Zhang L, Zhang H, Miao Y, Wu S, Ye H and Yuan Y: Protective effect of allicin against acrylamide-induced hepatocyte damage in vitro and in vivo. Food Chem Toxicol 50: 3306-3312, 2012

39. Chow CK: Nutritional influence on cellular antioxidant defense systems. Am J Clin Nutr 32: 1066-1081, 1979.

40. Cheeseman KH, Burton GW, Ingold KU and Slater TF: Lipid peroxidation and lipid antioxidants in normal and tumor cells. Toxicol Pathol 12: 235-239, 1984. 